Methods: A 14-question survey was administered via structured interviews to individuals occupying activated HEICS leadership positions at the NCKUH about the organization, structure, and function of the HEICS units and sub-units they led and the job actions they performed from 25 March to 16 June 2003.

Results: A total of 33 persons (87\%) occupying 39 of 44 (89\%) activated HEICS leadership positions directly participated in the survey. Collectively, the participants reported: (1) the creation of four new HEICS unit leaders and corresponding units during the outbreak, including the infection control officer (management section) and the SARS assessment, isolation, and critical care unit leaders (operations section); and (2) the creation of six new HEICS sub-units, including functional areas for fever screening, the SARS assessment, and resuscitation outside of the hospital, and SARS patient care, SARS critical care, and employee isolation inside the hospital; and (3) the performance of new job actions related to infection control by all HEICS unit leaders.

Conclusions: The HEICS provides a flexible framework that appears to have assisted the NCKUH in the organization of its emergency response to the SARS outbreak in Taiwan.

Keywords: coordination and control; hospital emergency incident command system (HEICS); implementation; outbreak; severe acute respiratory syndrome (SARS); Taiwan Prebosp Disast Med 2005;20(2):s39-s40

\section{Pandemic Planning for Primary Care: How to Set $U p$ a Community Assessment Center}

M. McLean; ${ }^{1}$ B. Borlase, ${ }^{2}$ S. Miller ${ }^{3}$

1. Regional Public Health, New Zealand

2. Allen and Clarke Regulatory Consultants, New Zealand

3. Capital and Coast District Health Board, New Zealand

New Zealand has strengthened its national pandemic plans over the past two years. However, the organization of primary care in a pandemic has received less attention, even though this sector is both essential and highly vulnerable in a pandemic. A review of the literature suggests that this situation may be common in other countries. The concept of non-traditional sites for delivery of basic health services is mentioned in a number of national plans, but often do not appear to be fully developed.

This presentation will describe a project in Wellington, New Zealand, which assessed whether community-based assessment centers (CACs) would be feasible in the region. Community-based assessment centers are defined as centers which would provide triage, initial assessment, and outpatient management of cases of pandemic illness. The rationale is to streamline services, relieve the burden on other primary care services, and improve triage to secondary care. Such centers also could be used to distribute antiviral medication and vaccines.

Based on the literature, a checklist for CACs was developed. This checklist then was used to assess potential sites in the region. Using FluAid, the anticipated excess consultations in primary care were assessed, as well as whether the proposed sites could cope with the load.

This study concluded that CACs are feasible and would be a useful part of the primary care response to a pandemic. Considerable detailed planning is required in the interpandemic period, including funding, supplies, development of detailed resources, and a strong focus on infection control training in primary care.

Keywords: community-based assessment centers ( $\mathrm{CACs}$ ); pandemic; primary care; review Prehosp Disast Med 2005;20(2):s40

\section{Theme 10: Planning for Mass Gatherings}

Chairs: Andrew Bacon; Demetrios Pyrros

\section{Haji: The Oldest and Largest Mass Gathering \\ I. Alshinkity \\ Alnoor Specialist Hospital, Saudi Arabia}

Introduction: Hajj is an annual, six-day, religious event, in which $>2.5$ million Muslims from $>140$ countries, including Saudi Arabia, gather at the holy shrine of Mecca to perform this cornerstone ritual of Islam. This study aimed to give an overview of Hajj and the different health problems repeatedly encountered in this event.

Methods: An extensive review was conducted using the computerized databases Medline and Medscape for searches from 1960 through September 2004. Articles containing information pertaining to Hajj were read, abstracted, analyzed, and compiled.

Results: Various large-scale, health problems and critical illnesses were reported during Hajj. Non-communicable problems included stampede mass casualties, motor vehicle trauma, fire-related burn injuries, skin diseases, accidental hand injury during animal slaughter, under-utilization of automated external defibrillators (AEDs), and terrorist actions. Communicable problems included outbreaks of multiple infectious diseases; for example, a new strain meningococcal meningitis and Rift Valley encephalitis.

Conclusions: Hajj represents a challenge to Saudi health authorities. Hajj reconnaissance and developing an understanding of various factors and problems associated with it should be the first step for planning, prevention, and resource allocation of hazards.

Keywords: disease; Hajj; mass gathering; Saudi Arabia Prehosp Disast Med 2005;20(2):s40

\section{Emergency Planning for Mass Gatherings at Dragon Stadium in Porto, Portugal}

R. Resende; A. Puga; A. Pereira; A. Ferreira; P. Coelho Portugal

Football, or soccer as it is called in the United States, is probably the most popular sport in Europe. The passion people have for it makes football games, especially those of the Europe Cup, mass gatherings with special characteristics. History has presented us with sad examples of what can happen if things go wrong during football matches.

The Dragon Stadium at Porto is a new UEFA, five-star facility that frequently holds major football events, such as Portuguese Superleague games and Champions League matches. The average attendance is well over 30,000 people per game. 